\title{
Cobb Syndrome: A Case Report with Review of Clinical and Imaging Findings
}

\author{
Alok Bhatt, Peter Kalina* \\ Department of Radiology, Mayo Clinic, Rochester, MN, USA \\ Email: "kalina.peter@mayo.edu
}

Received 18 September 2014; revised 18 October 2014; accepted 18 November 2014

Copyright (C) 2014 by authors and Scientific Research Publishing Inc.

This work is licensed under the Creative Commons Attribution International License (CC BY). http://creativecommons.org/licenses/by/4.0/

(c) (i) Open Access

\begin{abstract}
Cobb syndrome is a rare entity characterized by cutaneous vascular lesions and arteriovenous malformations in the spine, both in the same metamere. This syndrome is also known as cutaneous vertebral medullary angiomatosis, cutaneomeningospinal angiomatosis, and spinal arterial metameric disorder. We report the case of a male infant diagnosed with Cobb syndrome who was treated surgically. The presence of a cutaneous vascular lesion in this patient prompted subsequent imaging for spinal angioma or AVM in the same dermatome. Early recognition in this patient was shown to be life-changing, as patients with Cobb syndrome who have undergone early intervention have shown to be without neurologic deficit or have a halt in progression of symptoms.
\end{abstract}

\section{Keywords}

\section{Cobb Syndrome}

\section{Introduction}

Cobb syndrome is a rare entity characterized by the combination of cutaneous vascular lesions and arteriovenous malformations involving the spinal cord, both in the same metamere. Originally first described by Berenbruch in 1890, recognition is now largely due to Dr. Stanley Cobb’s description in 1915 under the apprenticeship of Dr. Harvey Cushing [1]-[3]. Other synonyms for this syndrome include: cutaneous vertebral medullary angiomatosis, cutaneomeningospinal angiomatosis, and spinal arterial metameric disorder [4].

Patients can present at any age and may be asymptomatic. Others present with pain, numbness, or paresis. Since only about 40 cases have been reported in literature to date, treatment is variable, and may involve conservative therapy, embolization, or surgical resection [2] [5]. We report the case of a male infant diagnosed with Cobb syndrome who was treated surgically, without any subsequent neurological deficit.

${ }^{*}$ Corresponding author. 


\section{Case Report}

Our patient was a male infant of Somali descent, who was initially seen at an outside medical center for a bluish-red skin lesion involving the buttocks, which was becoming more apparent at 1 month of age. Outside medical records indicate the lesion was initially diagnosed as a diaper rash, and treated conservatively. Persistence of the lesion and a gradual increase in conspicuity lead to the diagnosis of a hemangioma, which was subsequently treated with laser therapy. One month after, at 3 months of age, the patient's skin started to break down, which prompted presentation to our institution for a second opinion.

Initial dermatologic physical examination from outside records noted a blue colored plaque over the cheeks of the buttocks (Figure 1). Ulcerations in the gluteal cleft and perianal region were documented after laser therapy. Neurology physical exam demonstrated a normal neurologic exam, without motor or sensory deficits.

An MRI of the sacrum was ordered to evaluate the subcutaneous extent of the presumed hemangioma. Initial images demonstrated multiple vascular flow voids within the soft tissues, which were not typical for subcutaneous extension of a dermal hemangioma (Figure 2). As a result, the exam was extended to include the thoracolumbar spine, which showed an enhancing oval-shaped mass in the spinal canal with associated serpiginous flow voids, compatible with an arteriovenous malformation (Figure 3, Figure 4). For surgical planning purposes, an MRA was also performed to demonstrate the extent of the AVM (Figure 5).

The patient was taken to the operating room, and upon incision from T12 to L2, neurosurgery reported a "large sausage-like mass entwined with the surrounding roots, including large tortuous vessels on the surface of the tumor. The mass appeared to connect to the filum terminale.” Pathology reported a benign vascular lesion composed of capillaries and large thick-walled vessels.

Approximately 1 week after surgery, the patient was seen as an outpatient with no neurologic deficits. Postoperative imaging demonstrated removal of the 'sausage-shaped mass' without residual AVM (Figure 6). Up to

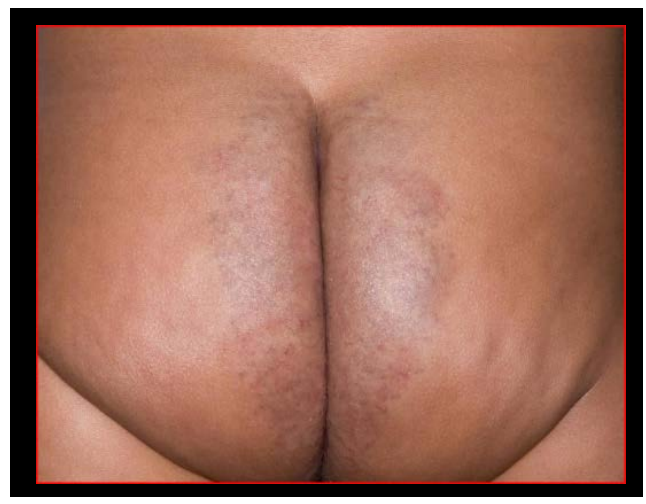

Figure 1. Photograph of the buttocks obtained at initial presentation, with the diagnosis of diaper rash.

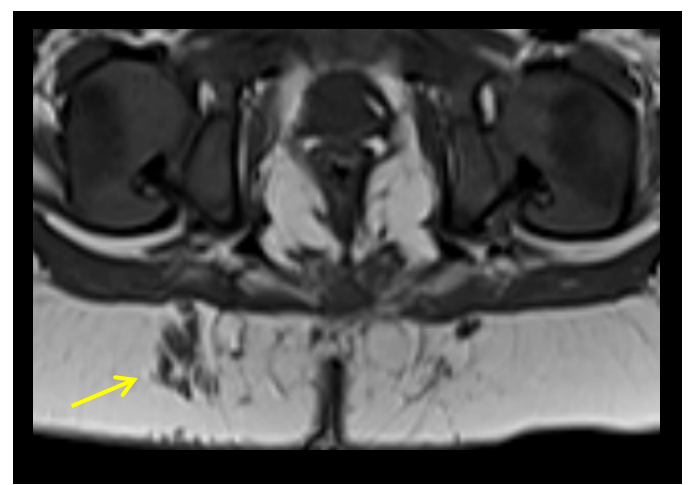

Figure 2. Axial T1-weighted image demonstrates multiple vascular flow voids in the paramedial buttock soft tissues (arrow), not typical in appearance for subcutaneous extension of dermal hemangioma. 


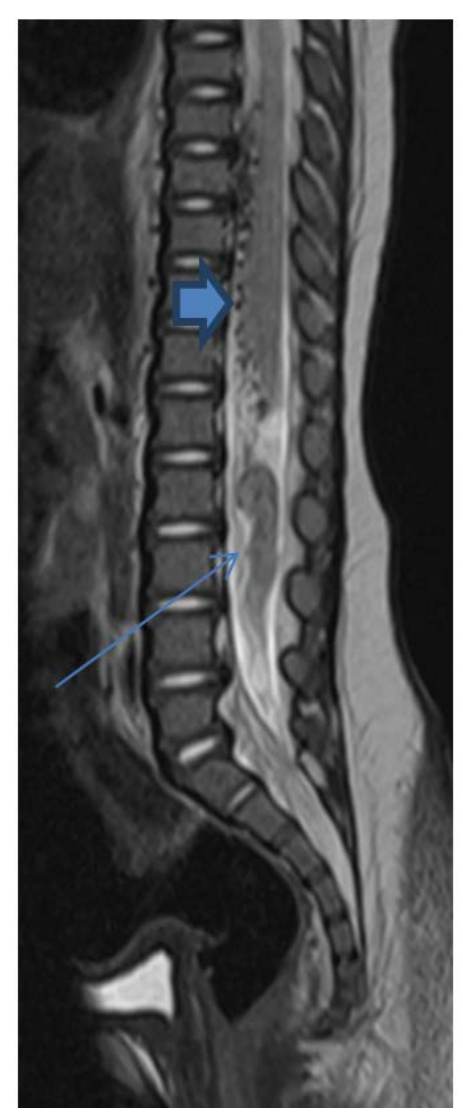

Figure 3. T2-weighted image demonstrates an elongated mass in the lumbar spinal canal (long arrow), with multiple serpiginous flow voids along the lowerventral thoracic cord (short arrow), extending inferiorly.

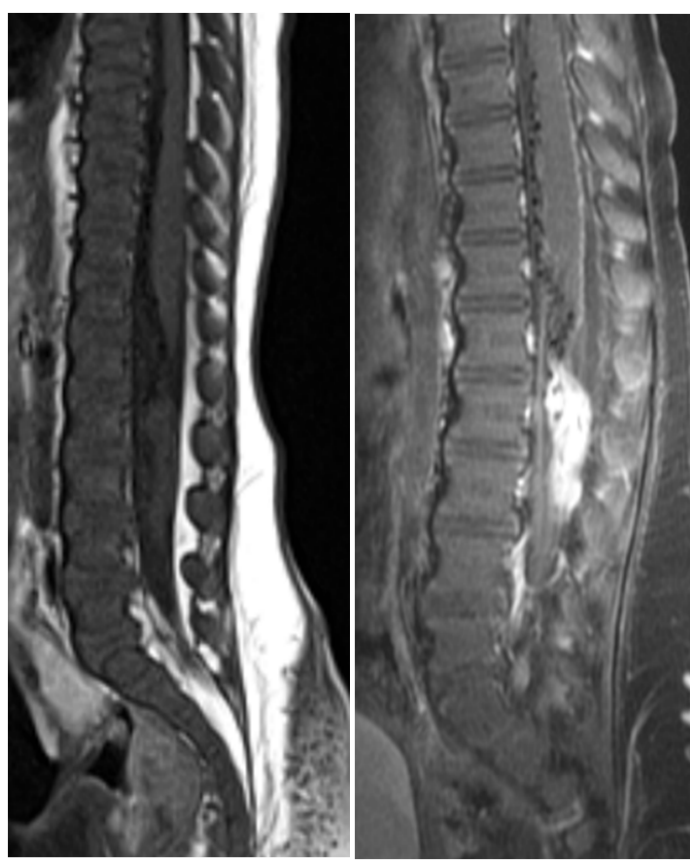

Figure 4. Pre- and post-contrast images demonstrate intense enhancement of this mass, with multiple flow voids leading to it. 


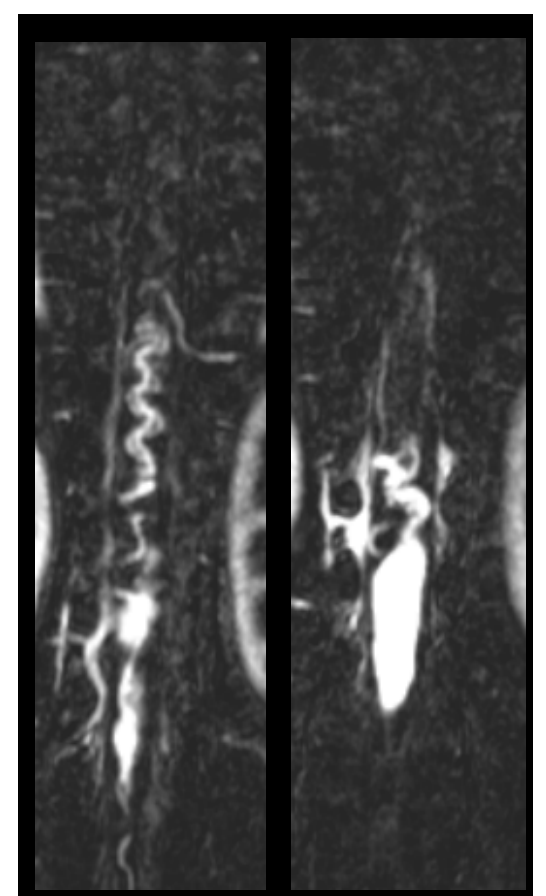

Figure 5. MRA demonstrates multiple serpiginous vessels extending up to the enhancing mass.

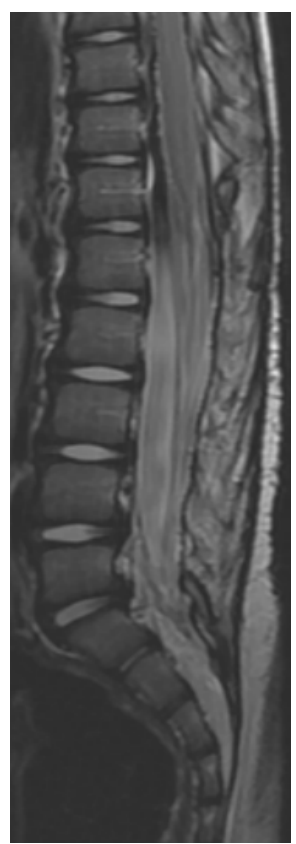

Figure 6. Post-operative T2-weighted image demonstrates removal of the mass without residual AVM.

the time of publication of this case report, the patient continues to have a normal neurologic exam with stable post-operative imaging.

\section{Discussion}

Cobb syndrome is a rare non-familial clinical entity which presents with a combination of cutaneous vascular 
lesions with arteriovenous malformations involving the spinal cord at the same metamere. The pathophysiology is hypothesized to be a defect in vascular cells during angiogenesis, which is propagated during migration and differentiation. The earlier the defect occurs in the vascular cells, the larger the impact on the number of downstream differentiated cells, and the higher the likelihood of metameric distribution. Location of the lesions at the same metamere is thought to be due to common embryologic origin of blood supply to the vertebrae and spinal cord [2] [5] [6]. As a result, a vascular skin lesion in a dermatomal distribution should raise the concern for a metameric abnormality.

Clinical presentation varies. Presentation may be at any age, but most commonly late childhood. The symptoms are thought to be due to a variety of factors, including cord compression by the AVM, "blood steal" resulting in cord ischemia, and venous hypertension [6]. Patients may present with monoparesis or sudden-onset of spastic quadriplegia. Other symptoms which have been reported in the literature are pain, headache, fever, gluteal and limb hypertrophy, as well as subarachnoid hemorrhage [2] [5] [7]. In extremely rare, and unfortunate incidences, the patient may present with Foix-Alajouanine syndrome, a constellation of acute/subacute myelopathy in the absence of hemorrhage caused by thrombosis of the AVM with the cord becoming necrotic [8].

Given only a few known cases in literature, the best course of treatment is difficult to plan. Options include surgery, endovascular embolization, and radiation, or any combination of these [5]. Soeda et al. has reported treatment of Cobb syndrome in an infant with corticosteroid therapy in combination with endovascular embolization [4]. The main goals of treatment are to prevent further decline of neurologic symptoms by reducing mass effect on the cord, venous hypertension, and vascular steal of blood supplying the nerve roots and spinal cord. Variable degrees of neurologic improvement have been reported [2]. A new or preexisting lesion may develop/grow due to a change in blood flow dynamics after treatment, and therefore, MRI/MRA surveillance imaging is indicated [2].

Our case serves to point out several encountered pitfalls before arriving at the correct diagnosis. Due to skin tone, the initial appearance of a cutaneous lesion on the buttocks was subtle, which first lead to the diagnosis of a diaper rash. Differential diagnoses given on imaging studies included ependymoma due to the enhancing mass, and hemangioblastoma due to the serpiginous flow voids, which lead to further uncertainty and confusion about treatment. A key finding in this case was the combination of a vascular skin lesion in a dermatomal distribution on physical exam and atypical vascular flow voids not characteristic for dermal extension of a hemangioma during imaging, which raised concern for a metameric abnormality, and the diagnosis of Cobb syndrome. Due to prompt treatment, the patient is now without any known neurologic deficit.

\section{Conclusion}

Cobb syndrome is a rare disorder of metameric abnormality, which may present at any age, and may be initially asymptomatic. The presence of a cutaneous vascular lesion should prompt subsequent imaging for spinal angioma or AVM in the same dermatome. As in this case, early recognition and intervention in patients with Cobb syndrome have proven beneficial to avoid future neurologic symptoms. In cases with presentation in late childhood, goals of treatment are to prevent further neurological deficits.

\section{Conflict of Interests}

The authors declare that there is no conflict of interests regarding the publication of this paper.

\section{References}

[1] Cobb, S. (1915) Hemangioma of the Spinal Cord: Associated with Skin Nevi of the Same Metamere. Annals of Surgery, 62, 641-649. http://dx.doi.org/10.1097/00000658-191512000-00001

[2] Schirmer, C.M., Hwang, S.W., Riesenburgery, R.I., et al. (2012) Obliteration of a Metameric Spinal Arteriovenous Malformation (Cobb Syndrome) Using Combined Endovascular Embolization and Surgical Excision. Journal of Neurosurgery, 10, 44-49. http://dx.doi.org/10.3171/2012.3.PEDS11530

[3] Maramattom, B.V., Cohen-Gadol, A.A., Wijdicks, E.F.M., et al. (2005) Segmental Cutaneous Hemangioma and Spinal Arteriovenous Malformation (Cobb Syndrome). Journal of Neurosurgery: Spine, 3, 249-252. http://dx.doi.org/10.3171/spi.2005.3.3.0249

[4] Soeda, A., Sakai, N., Iihara, K., et al. (2003) Cobb Sydrome in an Infant: Treatment with Endovascular Embolization and Corticosteroid Therapy: Case Report. Neurosurgery, 52, 711-715. 
http://dx.doi.org/10.1227/01.NEU.0000048483.21777.B7

[5] Clark, M.T., Brooks, E.L., Chong, W., et al. (2008) Cobb Syndrome: A Case Report and Systematic Review of the Literature. Pediatric Neurology, 39, 423-425. http://dx.doi.org/10.1016/j.pediatrneurol.2008.08.001

[6] Rodesch, G. and Lasjaunias, P. (2003) Spinal Cord Arteriovenous Shunts: From Imaging to Management. European Journal of Radiology, 46, 221-232. http://dx.doi.org/10.1016/S0720-048X(03)00093-7

[7] Gordon-Firing, S., Purriel, J.A., Pereyra, D., et al. (1981) Report of a New Case of Cobb Syndrome-Meningospinal Cutaneous Angiomatosis. Acta Neurológica Latinoamericana, 27, 99-111.

[8] Bordignon, K.C., Montu, M.B., Ramina, R., et al. (2005) Foix-Alajouanine Syndrome: Case Report. Arquivos de Neuro-Psiquiatria, 63, 527-529. http://dx.doi.org/10.1590/S0004-282X2005000300030 
Scientific Research Publishing (SCIRP) is one of the largest Open Access journal publishers. It is currently publishing more than 200 open access, online, peer-reviewed journals covering a wide range of academic disciplines. SCIRP serves the worldwide academic communities and contributes to the progress and application of science with its publication.

Other selected journals from SCIRP are listed as below. Submit your manuscript to us via either submit@scirp.org or Online Submission Portal.
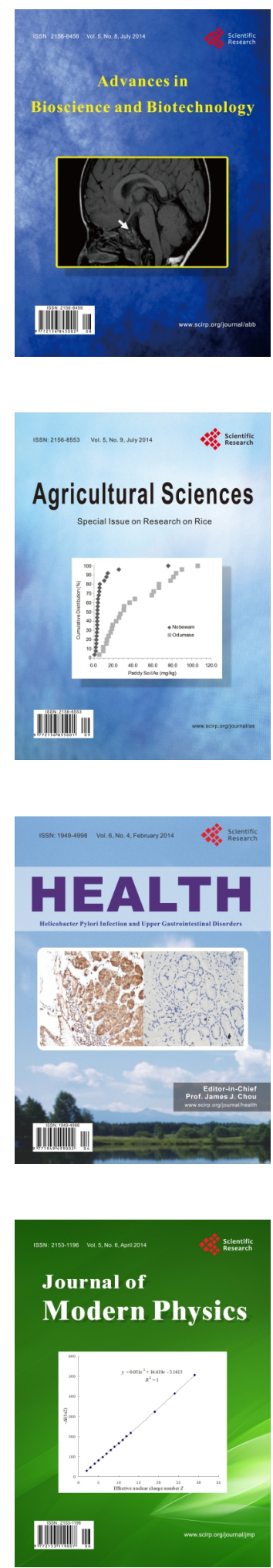
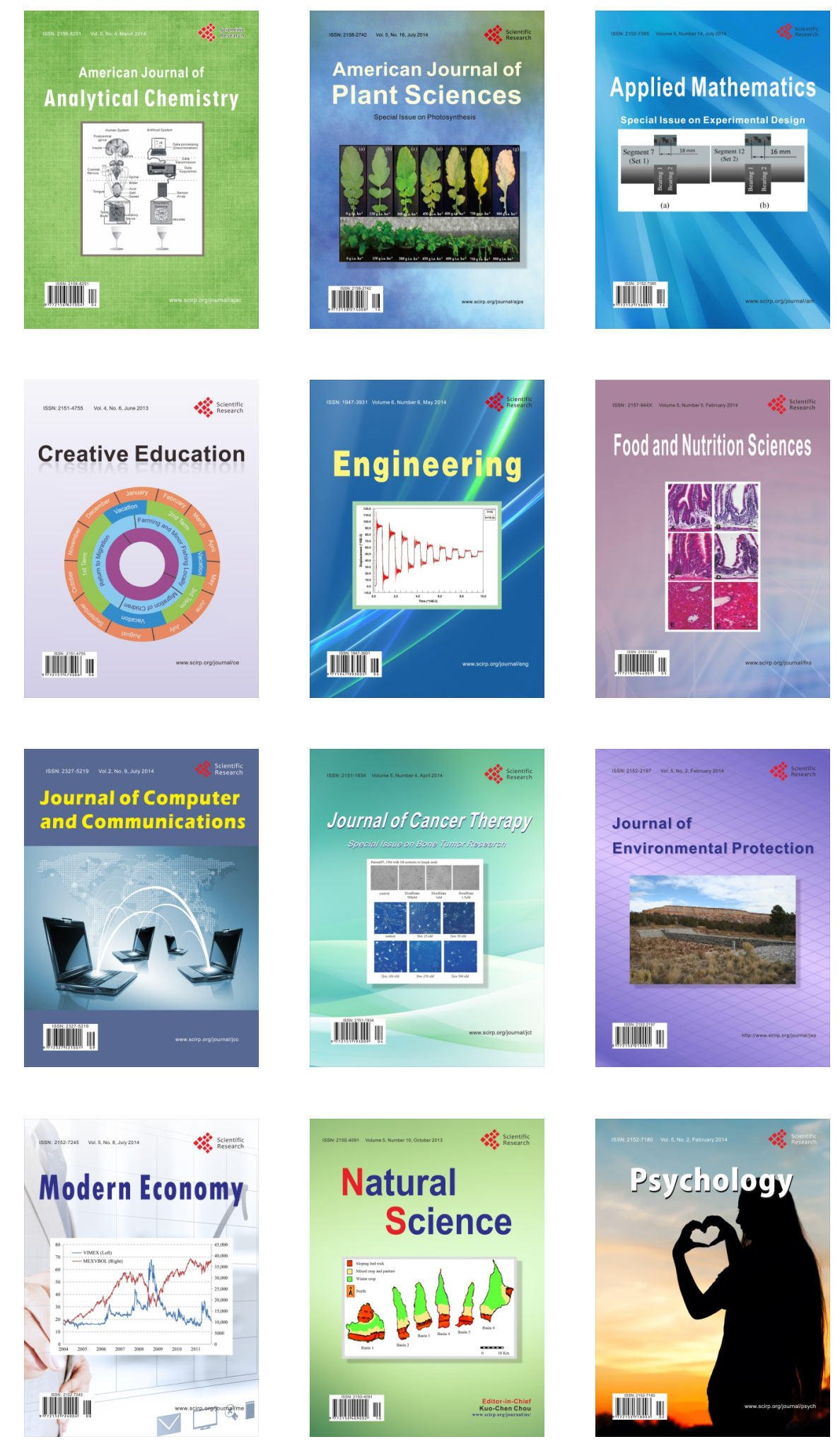